\title{
Schizophrenia and functional status
}

\author{
Esquizofrenia e funcionalidade
}

Karine Zortéa, ${ }^{1}$ Paulo Silva Belmonte-de-Abreu ${ }^{2}$

\section{Dear Editor,}

Bipolar disorder has been defined as a chronic, incapacitating condition that accounts for major functional impairment worldwide. ${ }^{1}$ However, we feel that it is important to remind our readers that major functional impairment is also present in schizophrenia, although it is rarely measured in a standardized way in these patients.

Functional status is a multidimensional concept that encompasses the subject's ability to perform daily activities and to participate in everyday situations, e.g., working, studying, living independently, having leisure time and keeping relationships. ${ }^{2}$

Functional and neuropsychological deficits are found in the majority of schizophrenic patients and they have a strong relationship with low education levels, severity of extrapyramidal symptoms, and major cognitive deficits. ${ }^{3}$ Differently from the episodic course of psychotic symptoms, functional impairment tends to remain stable for a long time in virtually all patients. ${ }^{4}$

There is a dearth of instruments specifically designed to measure functional status in psychiatric patients. The scales most frequently used include the Global Assessment of Functioning (GAF) scale, the Functional Status Questionnaire (FSQ), and the Psychosocial Aptitude Rating Scale (PARS). The Functioning Assessment Short
Test (FAST) has been developed by the Bipolar Disorder Program at the University of Barcelona, Spain, to assess functional impairment symptoms such as autonomy, occupational functioning, cognitive functioning, financial issues, interpersonal relationships, and leisure time. ${ }^{2}$ The instrument has been shown to adequately assess functional status in Brazilian patients. ${ }^{5}$

The Schizophrenia and Dementia Program (PRODESQ) at Hospital das Clínicas de Porto Alegre (HCPA) is currently analyzing the psychometric properties of the FAST scale, using a sample of approximately 100 patients with schizophrenia and 100 paired controls, with a focus on producing a valid and reliable instrument for the assessment of functional status in schizophrenia.

As a preliminary finding, we would like to describe the case of a patient diagnosed with schizophrenia 9 years before the beginning of the present investigation, disease onset at 16 years of age, under treatment with clozapine ( $300 \mathrm{mg} /$ day) for 3 years. The paired control did not have a diagnosis of mental disorders, had no family history of mental disorders and was not under pharmacological treatment. The results show the applicability and usefulness of the FAST scale in patients diagnosed with schizophrenia, as well as a clear difference in the assessment of healthy controls of similar age, ethnic origin, and education level (Table 1).

\footnotetext{
${ }_{1}$ Mestre. Nutricionista. Serviço de Psiquiatria, Laboratório de Psiquiatria Molecular, Hospital de Clínicas de Porto Alegre (HCPA), Porto Alegre, RS, Brazil. ${ }^{2}$ PhD. Psiquiatra. Programa de Pós-Graduação em Ciências Médicas: Psiquiatria, Universidade Federal do Rio Grande do Sul (UFRGS), Porto Alegre, RS, Brazil.

Financial support: Fundo de Incentivo à Pesquisa e Eventos - Hospital de Clínicas de Porto Alegre (FIPE-HCPA), Conselho Nacional de Desenvolvimento Científico e Tecnológico (CNPq), Institutos Nacionais de Ciência e Tecnologia (INCT/CNPq).

Submitted Jan 25 2011, accepted for publication Aug 24 2011. No conflicts of interest declared concerning the publication of this letter.

Suggested citation: Zortéa K, Belmonte-de-Abreu PS. Schizophrenia and functional status [letter]. Trends Psychiatry Psychother. 2012;34(1):42-3.
} 
Table 1 - Characteristics of a patient with schizophrenia compared with a healthy control

\begin{tabular}{lcc}
\hline & Patient & Control \\
\hline Age (years) & 25 & 25 \\
Sex & Male & Male \\
Education (years of schooling) & 8 & 10 \\
Ethnic origin & Caucasian & Caucasian \\
Clinical status & & \\
$\quad$ Total BPRS score & 38 & - \\
$\quad$ Positive symptoms & 6 & - \\
$\quad$ Negative symptoms & 6 & - \\
$\quad$ Total FAST score & 68 & 10 \\
FAST domains & & 2 \\
$\quad$ Autonomy & 11 & 2 \\
$\quad$ Occupational functioning & 15 & 3 \\
$\quad$ Cognitive functioning & 14 & 2 \\
$\quad$ Financial issues & 6 & 1 \\
$\quad$ Interpersonal relationships & 16 & 0 \\
$\quad$ Leisure time & 6 & \\
\hline
\end{tabular}

BPRS = Brief Psychiatric Rating Scale; FAST = Functioning Assessment Short Test.

Psychotic symptoms, comorbidities, as well as functional and cognitive impairment significantly and independently affect the quality of life of patients with schizophrenia. In this sense, obtaining valid and reliable instruments, capable of adequately assessing the functional domains in schizophrenia, is extremely important.

\section{References}

1. Cacilhas AA, Magalhães PV, Ceresér KM, Walz JC, Weyne $F$, Rosa $A R$, et al. Bipolar disorder and age-related functional impairment. Rev Bras Psiquiatr. 2009;31:354-7.

2. Rosa AR, Sánchez-Moreno J, Martínez-Aran A, Salamero $M$, Torrent $C$, Reinares $M$, et al. Validity and reliability of the Functioning Assessment Short Test (FAST) in bipolar disorder. Clin Pract Epidemol Ment Health. 2007;3:5.

3. Patterson TL, Klapow JC, Eastham JH, Heaton RK, Evans $J D$, Koch WL, et al. Correlates of functional status in older patients with schizophrenia. Psychiatry Res. 1998;80:41-52.

4. Niendam TA, Bearden CE, Johnson JK, McKinley M, Loewy $R$, O'Brien M. Neurocognitive performance and functional disability in the psychosis prodrome. Schizophr Res. 2006;84:100-11.

5. Cacilhas AA, Magalhães PV, Ceresér KM, Walz JC, Weyne F, Rosa $A R$, et al. Validity of a short functioning test (FAST) in Brazilian outpatients with bipolar disorder. Value Health. $2009 ; 12: 624-7$

\section{Correspondence:}

Karine Zortéa

Av. Protásio Alves, 7157/203A, Petrópolis

91310-003 - Porto Alegre, RS - Brazil

Tel. : +55 (51) 8429.6901, +55 (51) 2101.8846

E-mail: karine.personaldiet@gmail.com 